\section{De la invisibilidad} a la multiplicidad: movilizaciones, ontologías e imaginarios urbanos en torno a la defensa de los humedales de Valdivia

From invisibility to multiplicity: mobilizations, ontologies and urban imaginaries around the defense of Valdivia's wetlands

\section{Claudia Sepúlveda-Luque \\ MontserRat LaRa-Sutulov ${ }^{* *}$ \\ Surimana PÉrez ${ }^{\text {** }}$ \\ FELIPE GUERRA ${ }^{* \star * \star}$ \\ Clarena RodríGuez ${ }^{\star * \star * \star}$ \\ ANDREA PINO ${ }^{* * *+* *}$}

Centro Transdisciplinario de Estudios Ambientales y Desarrollo Humano Sostenible, Universidad Austral de Chile, (CEAM) Valdivia.claudia.sepulveda.luque@gmail.com

** CEAM-Valdivia, montselara@gmail.com

*** Equipo de Investigación Proyecto Fondecyt 1141011 CEAM-UACH

**** CEAM-Valdivia.

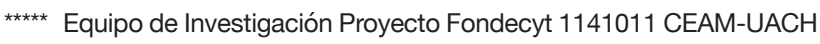
${ }^{\star \star \star \star \star \star ~ C E A M-V a l d i v i a . ~}$

\section{Resumen}

Los ambientes inundados que hoy llamamos humedales han estado presentes en Valdivia desde antes de su fundación, en 1552. Sin embargo, solo adquirieron un carácter polémico, capaz de movilizar imaginarios urbanos alternativos, como efecto del desastre del Río Cruces, ocurrido cinco siglos más tarde, a partir del 2004. Este artículo explora los efectos generativos que dicho desastre tuvo en la relación de los valdivianos con los humedales urbanos. Proponemos que el desastre del Rio Cruces provocó que estos humedales fueran "descubiertos" por los valdivianos, quienes comenzaron a movilizarse en su defensa. A través de estas movilizaciones, y en contraste con la débil existencia que estos ecosistemas siguen teniendo en el marco legal e institucional del país, en Valdivia los humedales adquirieron una "ontología fuerte". Es decir, una existencia cada vez más "densa", a medida que se fueron entrelazando con la de sus habitantes. Junto a esta densidad ontológica, los humedalesconvertidos ahora en actores- han sido capaces de encauzar medidas y recursos en favor de su protección junto a nuevos imaginarios de una ciudad donde estos ambientes puedan ser integrados a la vida cotidiana de sus habitantes.

Palabras clave: Humedales, Valdivia, Ontologías, Multiplicidad, Movilizaciones.

\begin{abstract}
The permanently flooded environments that we now call wetlands have been present in Valdivia prior to its foundation, in 1552. Nevertheless, they only acquired a polemical character, able
\end{abstract}


to mobilize alternative urban imaginaries, as an effect of the Rio Cruces disaster, occurred five centuries later, since 2004. In this paper we explore the generative effects that such disaster had in the relation between Valdivians and urban wetlands. We propose that the Rio Cruces disaster provoked these wetlands to be "discovered" by Valdivians, who begun to mobilize in their defense. Through such mobilizations, and in contrast with the weak existence that these ecosystems continue to have in the country's legal and institutional framework, in Valdivia wetlands acquired a "strong ontology". That is, an increasingly dense existence, as they became entangled with that of its inhabitants. Along with such ontological density, wetlands -now turned into actors- have been able to channel measures and resources in favor of their protection, as well as imaginaries of a city where these environments can be integrated to the everyday lives of its inhabitants.

Key words: Wetlands, Valdivia, Ontologies, Mobilizations, Multiplicity.

\section{Introducción}

La ciudad de Valdivia (3948'30"S, $73^{\circ} 14^{\prime} 30^{\prime \prime} \mathrm{O}$, 166 mil habitantes) ha sido escenario de movilizaciones consideradas entre las más emblemáticas de la historia ambiental de Chile. Es el caso del conflicto surgido en respuesta al desastre del Santuario de la Naturaleza del Río Cruces -uno de los mayores humedales del país- ocurrido desde el 2004 (Sepúlveda y Bettati 2005; Rivera 2010). La movilización resultante, protagonizada por la agrupación ciudadana Acción por los Cisnes, provocó la revisión de las instituciones ambientales del país, vigentes desde 1994, al demostrar su implicación en la producción del desastre (El Mercurio 24 noviembre 2005, 12 junio 2008; Pizarro 2007; Radio Cooperativa 2 mayo 2007; Tecklin et al. 2011). Ello generó un quiebre institucional determinante para reformar dicho marco legal ambiental, reforma resistida durante más de una década por los gremios empresariales (El Mercurio 10 de junio de 2005; Sepúlveda y Rojas 2010; Sepúlveda y Villarroel 2010). Así, el desastre del Río Cruces generó efectos perdurables y de largo alcance cuyas huellas se evidencian en el actual marco regulatorio ambiental del país (Sepúlveda 2016, 2018).

Un segundo efecto perdurable de este desastre, fue hacer visibles a los humedales como objetos de las políticas públicas. Antes del 2004 el término "humedal" era desconocido en Chile por el público general, siendo utilizado solo en círculos académicos y ambientales. La movilización valdiviana, centrada en la defensa de los cisnes de cuello negro y de su hábitat -el humedal del Río Cruces- puso a estos ecosistemas, literalmente, en la primera plana del debate nacional. Miles de notas de prensa y, sobretodo, cientos de imágenes de cisnes agónicos hicieron imposible continuar ignorando la existencia de los humedales, cuyo valor ecológico y fragilidad quedaron evidenciados de manera dramática (Sepúlveda 2018). Producto de esta visibilidad, el 2005 la entonces Comisión Nacional del Medio Ambiente (CONAMA) elaboró la primera

En cuanto a la empresa responsable, la movilización la obligó a reformular sus políticas y puso en riesgo la continuidad de su negocio, según han reconocido sus ejecutivos (Seminario FACEAUACH, enero 2013). La empresa además fue declarada culpable de daño ambiental por los tribunales de justicia en el 2013. De la crisis causada por el desastre también se derivaron cambios en la gestión ambiental y social de otras empresas (Geisse y Berdichevsky, comunicación personal). 
Estrategia Nacional de Humedales ${ }^{2}$, dando así un primer paso para ponerse al día con la protección de estos ecosistemas considerados de primera prioridad a nivel mundial (CONAMA 2005, 2005b; Tecklin et al. 2015; ONU 2013). El respectivo Plan de Acción se enfocó en generar conocimiento sobre los humedales junto al "cambio cultural" necesario para su mayor valoración social. En palabras de una profesional del Ministerio de Medio Ambiente (MMA) -continuador de la CONAMA- con dicho enfoque se buscaba "cambiar primero la conducta" antes de "lograr una protección legal" de los humedales ${ }^{3}$. Esto explica que, a pesar de comenzar a ser reconocidos como objetos de la política ambiental, el consiguiente reconocimiento jurídico de los humedales nunca se priorizó. Por carecer estos ecosistema de un reconocimiento legal adecuado, resultaba a su vez imposible avanzar en su protección efectiva ${ }^{4}$. De allí que el MMA promoviera la aplicación de ordenanzas municipales para proteger los humedales del país, herramienta de rango legal inferior, insuficiente para tal fin ${ }^{5}$.

\footnotetext{
La Estrategia Nacional para la Conservación y Uso Racional de los Humedales en Chile (2005), definió como su objetivo "promover la conservación de los humedales prioritarios de Chile y de sus funciones y beneficios en un marco de desarrollo sustentable" (CONAMA 2005).

3 Entrevista citada por Tecklin et al. 2015

4 Tanto la Estrategia de Humedales como su Plan de Acción fueron criticados por consistir en una "mera enunciación de principios" y contener medidas "generales y vagas", sin efectos medibles. En su evaluación del Programa de Recursos Naturales y Biodiversidad de CONAMA realizado el 2008, Arenas et al. (2008: 104) concluyen que los indicadores de cumplimiento del Plan de Acción de humedales corresponden a meras "acciones administrativas", tales como creación de grupos de trabajo o implementación de procedimientos de información. El citado informe concluye que "sin la información de cómo varía el estado de los ecosistemas, no es posible fundamentar algún juicio acerca de la efectividad de las políticas públicas que buscan protegerlos".
}

5 Ver Tecklin, Sepúlveda y Lara (2015); Lara Sutulov (2017).
Con todo, durante el 2011 el MMA elaboró el primer inventario nacional de humedales, cumpliendo así un compromiso adquirido por Chile al suscribir la Convención Ramsar, en $1981^{6}$. Dicho inventario definió y clasificó a los humedales, evaluando su estado de conservación ${ }^{7}$. Como efecto, los humedales de Chile dejaron de ser entidades abstractas y genéricas para convertirse, por fin, en ecosistemas concretos e individualizables. Es decir, en ecosistemas "con nombre y apellido". En otras palabras, cada uno de los humedales del país cobró existencia material. Más recientemente, el Plan de Acción para la Conservación de Humedales fue incorporado el 2017 a la Estrategia Nacional de Biodiversidad (MMA 2017). Por otra parte, hoy se analiza en el Congreso la forma de incluir la protección de humedales en la ley que creará el Servicio de Biodiversidad y Áreas Protegidas y el Sistema Nacional de Áreas Protegidas (Boletín $N^{\circ}$ 9.404-12) y, de forma indirecta, en la reforma al Código de Aguas de 1981 (Boletín № 754312), que aborda la protección de las funciones ecosistémicas de los cuerpos de agua.

La Convención Relativa a los Humedales de Importancia Internacional especialmente como Hábitat de Aves Acuáticas, conocida como Convención Ramsar, fue ratificada por Chile en 1981 (DS N771 del Ministerio de Relaciones Exteriores). Es el primer y único cuerpo legal vigente en Chile en relación a los humedales. Mandata al Estado a proteger, conservar y propender hacia el uso racional de estos ecosistemas en todo el país. Además, obliga al Estado a contar con una estrategia nacional de humedales e instrumentos como un catastro nacional, normas de protección, incentivos para el manejo sustentable, programas de monitoreo, investigación y educación. La definición de humedal utilizada en Chile por los organismos competentes es la aportada por la Convención Ramsar que incluye a todos los cuerpos de agua tales como "marismas, pantanos y turberas, o superficies cubiertas de aguas, sean éstas de régimen natural o artificial, permanentes o temporales, estancadas o corrientes, dulces, salobres o saladas, incluidas las extensiones de agua marina cuya profundidad en marea baja no exceda de seis metros".

7 Actualmente este inventario se actualiza de forma periódica y es de acceso público a través de la plataforma en línea: http:// humedaleschile.mma.gob.cl/ 
Finalmente, también se analizan mecanismos legales para la protección de humedales urbanos (Boletín No 11256-12).

Recuadro 1: En Chile los humedales se distribuyen a través de todo el territorio nacional. A lo largo de la costa toman la forma de estuarios, lagunas costeras y marismas, mientras en la cordillera corresponden a salares, lagunas salobres, bofedales y lagunas altoandinas. En la zona sur son conocidos como ñadis y mallines o turberas. Un caso especial son los hualves o bosques pantanosos, característicos de la Región de Los Ríos, cuya superficie ha disminuido severamente (Gobierno de Chile 2015).

Según el Inventario de Humedales del Ministerio de Medio Ambiente (MMA 2011) hoy existen 1,5 millones de hectáreas de humedales a lo largo del país, lo que corresponde al $3 \%$ de la superficie continental de Chile. Esta estimación no considera los humedales de las islas oceánicas ni las turberas o mallines de la zona sur austral (Aysén, Magallanes y Antártica Chilena).

En relación a su estado de conservación, los humedales alto-andinos y turberas son los más frágiles debido al carácter único de sus componentes hídricos y vegetacionales (MMA 2011). A su vez, los humedales costeros están en condición crítica, siendo los de la zona norte del país -hasta la Región del Maule- los que presentan un mayor grado trófico (eutróficos a hiper eutróficos) por menor disponibilidad de agua y usos consuntivos de la minería y la agricultura (MMA 2011).

Fuentes: Tecklin, Sepúlveda y Lara (2015); Gobierno de Chile (2015); MMA (2011); MMA (2013).

A pesar de haber sido clasificados e inventariados, "en Chile los humedales legalmente no existen", como concluyó un informe sobre humedales costeros de Chiloé encargado por la Fundación Packard (Tecklin, Sepúlveda y Lara 2015). En efecto, de los 55 cuerpos legales que son aplicables a los humedales -ya sea al uso o manejo del suelo, agua o especies que los componen (Möller \& Muñoz-Pedreros 2014)- ninguno considera a los humedales como ecosistemas en sí mismos, es decir, con sus atributos y funciones propias (Guerra y Lara-Sutulov 2017). Más aún, 8 de las normas existentes incentivan directa o indirectamente la destrucción de humedales por medio de su drenaje o relleno ${ }^{8}$ (Möller \& MuñozPedreros 2014). Como resultado, los únicos humedales protegidos legalmente en Chile lo son por defecto, por estar localizados dentro de áreas protegidas oficiales ${ }^{9}$. Para el resto, la protección solo es posible a través de normas referidas a algunos de sus componentes por separado (p.e. bosques, fauna, agua). Con ello, las cualidades y valores de los humedales en cuanto ecosistemas en sí mismos, más allá de sus componentes, son ignoradas por el marco legal actual (Guerra y Lara-Sutulov 2017).

\footnotetext{
Dentro de este universo destacan, entre otras, los siguientes cuerpos legales por su aplicación e incidencia sobre los humedales: Ley No 19.300 sobre Bases Generales del Medio Ambiente; Ley No 20.283 sobre Recuperación del Bosque Nativo y Fomento Forestal y su Reglamento de Suelos, Aguas y Humedales (D.S. No 82/10 del Ministerio de Agricultura); D.S. No 40/12 Reglamento del Sistema de Evaluación de Impacto Ambiental; Ley No 19.473 de Caza,
}

9 Al2018,13 humedales que abarcan 361.761 ha cuentan en Chile con designación oficial como Sitios Ramsar, 7 de los cuales forman parte del Sistema Nacional de Áreas Protegidas del Estado (SNASPE). A su vez, 2 de estos sitios corresponden a Santuarios de la Naturaleza, una categoría de protección oficial. Sólo los Sitios Ramsar que son parte del SNASPE están sujetos a instrumentos de manejo, propios de las áreas protegidas en que se localizan. El 2010 CONAF formuló el primer programa nacional de conservación de humedales insertos en las áreas del SNASPE, Esta situación podría cambiar con la ley que crea el Servicio de Biodiversidad y Áreas Protegidas (SBAP), en actual discusión legislativa, que podría incorporar categorías y formas de protección oficial de los humedales. 
En suma, a diferencia de lo que sucedía hasta el 2004, cuando el desastre del Río Cruces ocurrió, la existencia de los humedales es hoy reconocida por las políticas ambientales de Chile. Más aún, estos ecosistemas han comenzado a ser definidos y clasificados en tanto objetos de atención, por parte del Estado y sus organismos. No obstante, tal reconocimiento no ha sido suficiente para que los humedales se constituyan en cuanto objetos con existencia legal, a los que puedan asociarse las respectivas medidas de protección. Esto los deja expuestos a una acelerada destrucción, como lo confirman informes públicos recientes (MMA 2011; MMA 2013; Gobierno de Chile 2015).

Podría decirse, por tanto, que los humedales tienen hoy en Chile una "ontología débil", término que aquí acuñamos en base a distinciones posthumanistas aportadas por la Ontología Política, como explicamos en la sección siguiente. Es decir, una existencia que, si bien es visible, carece de una "densidad" suficiente como para movilizar dispositivos jurídicos y acciones de política pública que ante las amenazas que los afectan- aseguren su permanencia material en el tiempo.

Recuadro 2: La relevancia ambiental y social de los humedales ha sido reconocida por las disciplinas ecológicas y los organismos internacionales.

En efecto, los humedales están clasificados entre los ecosistemas más frágiles y valiosos biológicamente a escala global, debido a que en ellos habita el $40 \%$ de las especies del planeta (Finlayson 2012). Los humedales desempeñan un papel crítico en la regulación de los ciclos hidrológicos, por lo que se asocian a servicios ecosistémicos fundamentales (Brinson y Eckles 2011; Fariña y Camaño 2012), tales como la provisión de agua para consumo humano, la protección frente a inundaciones y otros eventos climáticos, y la disponibilidad de hábitat para una alta diversidad de especies.

Consistente con ello, la Convención Ramsar -el tratado intergubernamental para la conservación y uso racional de humedalesseñala que "los humedales son los recursos principales de los que se derivan el agua y todos sus beneficios para los seres humanos y constituyen un componente decisivo y fundamental del ciclo hidrológico que mantiene nuestro abastecimiento de agua" (Convención Ramsar 2012) ${ }^{10}$.

El 2013, con ocasión del Día Internacional de los Humedales, la Organización de las Naciones Unidas emitió una declaración donde señalaba que la relación "entre el agua, las personas y los humedales siempre ha sido una preocupación central" y que por ser "un recurso de gran valor socioeconómico, cultural y científico (...) su pérdida sería irreparable" (ONU 2013) ${ }^{11}$.

Los humedales presentan altas tasas de destrucción en todo el planeta, estimándose que a comienzos del s. XX un $50 \%$ de su área total ha sido destruida (Finlayson 2012).

El argumento central que aquí proponemos es que, en Valdivia, la precaria existencia que los humedales tienen en Chile está siendo desafiada por un tercer efecto de largo plazo -

Convención Ramsar (2012). "Los Humedales Cuidan del agua" http://www.ramsar.org/sites/default/files/documents/library/ leaflet_s_0.pdf

$11 \mathrm{http} / / /$ www.unesco.org/new/es/media-services/single-view/news/ los_humedales_cuidan_del_agua/ 
esta vez local- provocado por el desastre del Rio Cruces: la inédita valoración social de los humedales urbanos, y las intensas controversias y movilizaciones que de ellas se derivan ${ }^{12}$. Dichas movilizaciones tienen como efecto desestabilizar la "ontología débil" o existencia precaria que los humedales tienen en las normas y políticas públicas, junto a sus restringidas posibilidades de protegerlos. En efecto, los humedales que toman forma en Valdivia por medio de las movilizaciones en su defensa se caracterizan por tener una "ontología fuerte". Es decir, una existencia densamente entrelazada con la vida cotidiana de los valdivianos. Esta "ontología fuerte" se expresa en los nuevos imaginarios de futuro para esta ciudad, desplegados en torno a la defensa de los humedales y dotados de la capacidad de modificar el devenir de la ciudad. Los humedales así performados también se diferencian de los que existieron en Valdivia antes del 2004, por lo que igualmente representan una inflexión ontológica en su trayectoria histórica.

En lo que sigue ampliamos esta perspectiva ontológica -tributaria de los enfoques posthumanistas y en particular de la Ontología Política-, para describir y explorar la inesperada figuración alcanzada por los humedales urbanos de Valdivia y sus consecuencias sociopolíticas. Para ello, planteamos primero el marco conceptual, centrado en las nociones

Entre tales controversias destaca la discusión en torno al Plan Regulador Comunal -el principal instrumento de planificación urbana-cuya elaboración se inició en Valdivia el 2004, coincidiendo con el mencionado desastre. Uno de los aspectos más polémicos de este nuevo plan regulador -que desde el 2014 se encuentra en revisión por la Contraloría- es la manera en que reclasifica a los humedales urbanos y facilita en algunos casos su relleno y posterior edificación. Otras controversias han girado en torno a obras de infraestructura urbana que amenazan la continuidad de algunos humedales, como es el caso de una carretera que podría dividir en dos al Humedal Angachilla, uno de los más emblemáticos para las movilizaciones ciudadanas. de "ontología débil" y "ontología fuerte" con que hemos descrito a los diferentes humedales que se confrontan en las disputas urbanas de Valdivia. Luego, presentamos la metodología de investigación. En tercer lugar, revisamos cómo se configuraron históricamente los humedales en Valdivia, y la forma en que se relacionaron con sus habitantes humanos. A continuación, analizamos los efectos ontológicos que las políticas públicas y normas generan en los humedales, tanto en Chile como en Valdivia, mostrando los diferentes humedales que cobran forma a través de ellas. En quinto lugar, describimos las movilizaciones en defensa de los humedales de Valdivia, junto a las nuevas prácticas sociales de relación con estos ecosistemas desplegadas localmente, mostrando los diferentes humedales que se asocian a ellas. Finalmente, abordamos los imaginarios alternativos de ciudad surgidos en torno a la defensa de los humedales, mostrando su agencia capaz de inflectar la trayectoria urbana de Valdivia.

\section{Marco conceptual}

Este trabajo se enmarca conceptualmente en los enfoques posthumanistas y su comprensión sobre el carácter performativo y múltiple de la realidad $^{13}$. Bruno Latour y Steve Woolgar (1979, 1986) describieron cómo los hechos científicos eran "fabricados" y luego "estabilizados" a través de un esfuerzo sostenido e incierto que involucraba a agentes humanos y nohumanos. A partir de entonces, los enfoques posthumanistas se centraron en mostrar que "la realidad no precede a las prácticas a través de las cuales interactuamos con ella. Sino que

Para una revisión más detenida de estos enfoques posthumanistas ver: Law (2008); Sepúlveda y Sundberg (2015); Escobar (2007a, 2007b); Sepúlveda (2016, 2018). 
toma forma por medio de tales prácticas" (Mol 1999: 75). Para referirse al proceso de cómo la realidad toma forma a través de las prácticas reiteradas de actores situados, los enfoques posthumanistas acuñaron el concepto de performación (Callon 2009, 2006).

La vertiente posthumanista de la Ontología Política -fundada por Annmarie Mol $(1999,2002)$ y ampliada por Mario Blaser $(2009,2010)$, John Law (2008) y Michel Callon (1986, 2006, 2009), entre otros- busca "subrayar el modo activo del proceso de dar forma a la realidad, y el que su carácter es a la vez abierto y sujeto a disputas" (Mol 1999: 75). Si la realidad 'se hace', dice Mol, y si es "histórica, cultural y materialmente localizada", se sigue que "también es múltiple" (Mol 1999: 75). Múltiple pero no plural, ya que la noción de multiplicidad acuñada por Mol apunta, no a la materialización de diferentes atributos de un mismo objeto unificado, sino a la materialización de diferentes versiones de dicho objeto: son "objetos diferentes y aún relacionados. Son formas múltiples de la realidad" (Mol 1999: 77). "Si la realidad es múltiple", concluye Mol, "también es política" (2002: 7). En efecto, "la realidad nunca es tan sólida que es singular. Siempre hay alternativas" Mol (2002: 164).

Para John Law (2008) la multiplicidad ontológica implica entender lo real como una materialización siempre saturada de poder. La pregunta no es, por tanto, qué realidad 'escogemos', sino "cómo interferir para difractar las realidades en lugares particulares y así generar alternativas" (2008: 637). Este es, precisamente, dice Law, el leitmotif del giro ontológico. De forma similar, a partir de sus estudios sobre performatividad económica, Michel Callon (2006) describió la realidad como un proceso ontológicamente fluido que resulta de la constante confrontación entre múltiples mundos que "intentan prevalecer" (Callon 2006: 28). Este enfoque supone, no solo rechazar la idea de singularidad ontológica propia de la Euro-modernidad (Blaser 2009), sino aceptar que 'la realidad' que emerge en cada momento y lugar es el producto contingente de disputas entre mundos $u$ ontologías que luchan por imponerse. Este enfoque abre así espacio a formas no-dominantes, invisibilizadas, de ser y conocer, cuyas huellas pueden ser 'trazadas' en las versiones dominantes de la realidad (Sepúlveda 2016, 2018).

Una noción clave de la Ontología Política es la de 'corpo-realización' desarrollada por Mario Blaser (2009). De acuerdo a ella, la realidad -por ejemplo, un determinado humedal- no sólo es resultado de la disputa entre múltiples versiones o posibles materializaciones de dicho objeto. A su vez, cada una de estas versiones puede cobrar mayor o menor "densidad ontológica" (Sepúlveda 2016) a medida que se entrelaza con el mundo por medio de las prácticas que la relacionan con actores situados. Siguiendo a Blaser, existirán por tanto versiones más "densas" o más "diluidas" de la realidad, condición que podrá variar históricamente según sea el resultado de las disputas ontológicas en curso.

Es a partir de la noción de la realidad como en permanente proceso de 'corpo-realización' que aquí proponemos la idea que los humedales -en su multiplicidad- pueden mostrar una versión con una "ontología fuerte" -es decir, más densao versiones con "ontología débil" -es decir, más diluida-. Dicho carácter ontológicamente "fuerte" o "débil" de los distintos humedales posibles de performar está dado, finalmente, por la densidad de las relaciones y entrelazamientos 
que estos objetos tengan con conocimientos, prácticas y recursos. Es en este sentido que decimos que los humedales performados en Chile a través de normas y políticas tienen una "ontología débil", es decir, una existencia incipiente, en proceso inicial de materialización y aún insuficiente para movilizar acciones en favor de su protección. En contraste, los humedales performados en Valdivia a través de las movilizaciones en su defensa -que son un objeto diferente- exhiben una "ontología fuerte". Es decir, densamente entretejida con conocimientos, actores e identidades. Es esta densidad ontológica la que, a su vez, permitiría comprender la agencia de los humedales performados localmente en Valdivia, los que como veremos- han sido capaces de desplegar imaginarios urbanos con el poder de afectar la trayectoria futura de la ciudad.

\section{Metodología}

Este trabajo presenta los resultados del Proyecto Fondecyt 1141011, cuyo objetivo fue caracterizar, describir y trazar materialmente los efectos ontológicamente generativos que el desastre del Río Cruces produjo en la sociedad valdiviana, con énfasis en el surgimiento de nuevas prácticas sociales y ontologías de relación con los humedales urbanos, describiendo sus expresiones y analizando sus consecuencias ecológicas, urbanísticas y sociopolíticas. Para ello se empleó una combinación de metodologías. En primer lugar, se describió la evolución histórica de las prácticas sociomateriales con que los habitantes de Valdivia se han relacionado con los humedales urbanos, en base a fuentes secundarias, principalmente históricas, que cubren desde la fundación de la ciudad, en
1552, hasta el presente, así como estudios arqueológicos del período pre-hispánico. El análisis se centró en las descripciones de cuerpos de agua correspondientes a la definición de humedal utilizada ${ }^{14}$, poniendo atención a eventos donde los humedales han participado en la constitución de la ciudad.

Por otra parte, se analizaron las descripciones referidas a humedales por parte de políticas públicas e instrumentos de planificación territorial ${ }^{15}$, junto a procesos administrativos 0 sentencias, a fin de observar la aplicación de normas jurídicas sobre humedales por parte de servicios públicos ${ }^{16}$. Esta información fue complementada con entrevistas a funcionarios públicos sobre las prácticas con que sus servicios se relacionan con los humedales de Valdivia.

En tercer lugar, se realizó un catastro de iniciativas de protección de humedales urbanos surgidas en Valdivia a partir del 2000, en base a fuentes secundarias, trazando su conexión con el desastre del Río Cruces y seleccionando

\footnotetext{
Los humedales fueron definidos por esta investigación como ecosistemas en transición, consistentes en un cuerpo saturado de agua con abundante materia orgánica vegetal de lenta descomposición que permite el desarrollo de biota adaptada a estas condiciones de vida. Posee suelos hídricos y vegetación hidrófita. Las diferencias radican en aspectos de funcionalidad, morfometría e hidrología.

15 Estos incluyeron: a) Estrategia de Desarrollo Regional de Los Lagos (2000) y Los Ríos (2009); b) Plan de Desarrollo Comunal de Valdivia (2010 y 2015); c) Plan Regulador Comunal de Valdivia (1988) y su actualización (2012); d) Plan Regional de Ordenamiento Territorial de la Región de Los Ríos (2015); e) I Plan Regional Intercomunal del Borde Costero de la Región de Los Ríos (2015); f) Plan Maestro de Aguas Lluvia de Valdivia (2015).

16 En particular, Dirección General de Aguas y Dirección de Obras Hidráulicas, ambas dependientes del Ministerio de Obras Públicas.
} 
cuatro para un estudio de $\operatorname{casos}^{17}$. Los casos seleccionados fueron estudiados para identificar las prácticas sociomateriales y de relación con los humedales, las visiones y enfoques sobre la ciudad que ellas movilizan y las consecuencias ecológicas, urbanísticas y sociopolíticas que de ellas se derivan. Con tal fin, se revisó información secundaria (literatura, informes, declaraciones públicas y prensa), se aplicaron entrevistas a dirigentes y vecinos, se realizó observación de terreno y se sistematizó la experiencia de los investigadores en algunas iniciativas.

\section{Relleno y destrucción: configuración histórica de una práctica dominante}

La ciudad de Valdivia se localiza en la confluencia de los Ríos Cruces, Valdivia, Calle-Calle y Cau-Cau, sobre depósitos fluvio-estuarinos, en una zona lluviosa (1.870 $\mathrm{mm}$ anuales $\left.{ }^{18}\right)$. Estos factores dan forma a una extensa red de humedales sobre los que se asienta la ciudad, la que Osorio (2009) Ilamó "el gran humedal de Valdivia".

Estos ambientes inundados estuvieron presentes en el espacio urbano de Valdivia desde antes de su fundación española (Guarda 2001). Aunque con otros nombres y otras prácticas asociadas, los humedales han estado siempre entrelazados con la identidad y la vida cotidiana de Valdivia y sus habitantes. Según registros arqueológicos, los ambientes

\footnotetext{
a) Parque Urbano y Deportivo Catrico; b) Reserva Natural Urbana en torno al Humedal Angachilla; c) Denuncia y movilización en torno al relleno del Humedal Cotapos; y d) Ordenanza Comunal de Humedales impulsada por la Red Ciudadana por los Humedales de Valdivia.

18 Dirección Meteorológica de Chile (http://www.meteochile.cl/
} PortalDMC-web/index.xhtml\#). inundados fueron importantes para los grupos humanos que habitaron este territorio antes de la llegada de los conquistadores (Otero 2006; Urbina y Adán 2012). Sus funciones incluyeron suelos de cultivo, provisión de agua y transporte fluvial (Guarda 1993; Bernales 1984).

Luego de la fundación española de Valdivia, en 1552 , los humedales marcaron de tal forma la estructura espacial de la urbe que Valdivia fue conocida como "la Ciudad del Lago" (Guarda 2001). Este imaginario queda ratificado en mapas españoles y holandeses de los siglos $X V I$ al XIX que muestran enormes lagunas en el centro de la ciudad (Jacques 2012; Siemsen 1855). Algunos textos destacan la "belleza" de los paisajes inundados, llamados "pitrantos" por los indígenas. En 1553 se construyeron en torno a ellos puentes de piedra para conectar las áreas separadas por las lagunas (Rosales 1877).

Del siglo XVIII datan las primeras descripciones que se refieren a estos sitios como "hualves", palabra indígena que fue traducida como "pantano", término que resalta la idea de estos sitios como zonas pestilentes y peligrosas. A pesar de ello, a fines de 1700s los "hualves" fueron integrados como parte del sistema de defensa militar de la ciudad ${ }^{19}$ (Guarda 2001). El uso de los humedales como agentes defensivos confirma no solo la visibilidad que alcanzaron sino la importancia que tuvieron al colaborar con la existencia y continuidad de Valdivia.

\footnotetext{
En 1779, un hualve en el interior de la ciudad, conocido como Laguna de San Antonio, fue intervenido para convertir la ciudad en una isla que conectara los ríos Calle-Calle y Valdivia. Se construyó un gran foso y muros de piedra en torno a este "pantano" para resguardar la ciudadela. El proyecto estuvo a cargo del ingeniero Antonio Duce. Aún se conservan los torreones Del Barro y Los Canelos, que marcaban los extremos del muro (Guarda 2001).
} 
Con la incorporación de Valdivia a la República de Chile, en 1820, los hualves comenzaron a ser considerados como "estorbos" en la tarea de convertir la ciudad en un lugar habitable. En 1846 un informe del intendente describía "trabajos de disección de varios hualves" que hacen "malsana la atmósfera y ocasionan algunas epidemias" (Jacques 2012). Los mapas de la época muestran lagunas que ocupaban la mitad de la superficie urbana (Siemsen 1855). Problemas sanitarios llevaron a las autoridades a pedir apoyo al gobierno nacional para secar los humedales.

A mediados del siglo XIX se inició el remate y privatización de los terrenos inundados, que durante la Colonia fueron considerados bienes públicos (Sitios Realengos). Los nuevos propietarios debían convertir los terrenos así adquiridos en sitios "útiles" en un plazo de cuatro años (Guarda 2001). La mayoría de las veces, lo anterior suponía su desecación y posterior relleno (Guarda 2001). Así, en menos de cuatro décadas las lagunas y "pantanos" desaparecieron por completo de los mapas de la ciudad (Boloña 1896).

A comienzos del siglo $X X$ los humedales se habían reducido notoriamente. Sin embargo, las nuevas áreas urbanas, destinadas a la población de menores recursos, convivían con amplios sectores inundados. Para 1920 las insalubres condiciones de vida de la población obrera asentada en las zonas bajas y vegas de la periferia de Valdivia, donde abundaban "pantanos" y "hualves", era el foco de una controversia nacional (Almonacid 2002; Rojas 2010).

Algunas décadas más tarde, las zonas inundadas volvieron a dominar el paisaje urbano de Valdivia de manera dramática. El gran terremoto de $1960^{20}$ provocó el hundimiento del suelo en hasta 2 metros (Rojas 2004). El posterior tsunami que afectó a la zona profundizó en otros 2 metros los cauces inferiores de los ríos que rodean la ciudad, generando riberas bajas y aguas someras. Como efecto, surgieron grandes humedales, como el Santuario del Río Cruces, hacia el norte de Valdivia, y el Angachilla, hacia el sur (Reinhardt et al. 2010). Por su parte, los barrios localizados en antiguas zonas de relleno se hundieron mientras las lagunas rellenadas a lo largo de dos siglos resurgieron dentro del perímetro urbano. Los humedales pasaron a ser nuevamente elementos "estructurantes" de Valdivia (Rojas Hoppe y Díez Lorente 2013).

Una gran parte de los terrenos nuevamente inundados correspondía ahora a propiedades privadas, en su mayoría vegas que antes del terremoto eran utilizadas con fines agropecuarios (Pérez Díaz 2015). En adelante, las controversias sobre la propiedad -pública o privada- y la facultad de rellenar los "nuevos" hualves y vegas que resultaron del terremoto han marcado el crecimiento urbano de Valdivia.

Desde 1990, el relleno de humedales pasó a ser parte de la política urbana oficial, como demuestra la solicitud del entonces Gobernador Provincial de Valdivia al Consejo de Defensa del Estado para que éste determinara si humedales originados en 1960 podían ser considerados legalmente como "terrenos inundados" (Consejo de Defensa del Estado 1991). En ese caso, se trataba de bienes fiscales susceptibles de ser destinados a la política pública habitacional

20 Este episodio no es único en su tipo. De acuerdos a varios cronistas, a lo largo de la historia de Valdivia se han registrado mega terremotos similares, como el ocurrido en 1575, con efectos devastadores sobre las poblaciones mapuche y española producto del los masivos hundimientos de tierra y los tsunamis provocados por los grandes ríos (Guarda 1993). 
por medio de obras financiadas por el Estado (Guerra y Lara-Sutulov 2017). Entre 1992 y 2007 la superficie urbana aumentó en un $64 \%$, provocando la desaparición de 20 ha de humedales y 40 de bosques (Osorio 2009; Jacques 2012). Actualmente, de las casi 8 mil hectáreas de superficie urbana de Valdivia, el $21 \%$ son humedales (MMA 2016). Si se incluyen los ríos esta cifra aumenta al 37\% (MMA 2016). Del total de humedales, 952 ha corresponden a vegetación herbácea de orilla, 317 ha a praderas perennes y 124 ha a bosque nativo en diferentes etapas de crecimiento (MMA 2016).

Como se desprende de esta revisión de la historia urbana de Valdivia, los humedales han tenido una vasta presencia en ella, ocupando hoy una proporción significativa del suelo urbano. De este protagonismo podría esperarse visibilidad y reconocimiento, así como un lugar claro en la identidad de la ciudad. Sin embargo, las políticas y narrativas urbanas de las últimas décadas han performado a los humedales de Valdivia como espacios marginales o sin valor -llamados legalmente "sitios eriazos"-, los que suelen terminar convertidos en microbasurales ${ }^{21}$. Se trata de humedales de "ontología débil”, es decir, cuya existencia es difusa, escasamente enlazada con la vida cotidiana de los valdivianos. Esta manera de performar los humedales vincula su existencia a la condición de haber sido previamente terrenos que la ciudad "perdió" con el terremoto de 1960. Por tanto, los atributos dominantes no son los ecológicos o ecosistémicos, sino su condición de suelos inundados que corresponde rellenar y "recuperar" como espacios edificables.

El concepto de "sitio eriazo" no solo tiene una connotación negativa sino efectos legales. Los terrenos eriazos no pagan impuestos. Mientras tanto, son rellenados clandestinamente y luego edificados (Art. 15 Ley 17235).
Esta performación de los humedales urbanos de Valdivia se ha visto reforzada por la escasez de terrenos urbanizables. Producto de la presión inmobiliaria se estima que unas 5 ha de humedales son rellenados cada año en Valdivia (Rojas Hoppe y Díez Lorente 2013). La práctica de relleno de humedales ocurre tanto a gran escala -por empresas inmobiliarias que utilizan maquinaria pesada, en especial para viviendas sociales- como a pequeña escala y de forma artesanal, por parte de propietarios que buscan ampliar sus propiedades o "recuperar" los suelos que el terremoto les arrebató.

La performación de los humedales como espacios urbanos devaluados se ve reforzada por vacíos en el dominio de la propiedad de los terrenos inundados por el terremoto de 1960. Siendo en su mayoría bienes fiscales según la legislación actual, estos terrenos nunca fueron inscritos a nombre del Fisco, lo que favorece su relleno, en especial en el caso de humedales localizados en terrenos privados. De forma concomitante, la manera en que los humedales son definidos por las políticas, normas e instrumentos de planificación también refuerza su performación como espacios sin valor en sí mismo y favorece su relleno, como veremos a continuación.

\section{Fragmentos de un objeto fracturado: las prácticas de los servicios públicos}

La performación históricamente dominante de los humedales urbanos de Valdivia, ya descrita, es sostenida y reproducida a través de la forma en que el marco legal define a estos ecosistemas y establece procedimientos en relación a ellos. Los objetos resultantes, interrelacionados aunque diferentes, tienen en común corresponder a 
fragmentos des-membrados de los ambientes húmedos que siempre son parte del espacio urbano valdiviano.

En efecto, las políticas y normas aplicables a los humedales se refieren solo a algunos componentes de estos ambientes (por ejemplo, agua o suelo), ignorando su condición de ecosistemas complejos, con propiedades únicas, como los "hualves" descritos por los cronistas del siglo XVI (Pérez Díaz 2015; Guerra y Lara-Sutulov 2017). De esta forma, los humedales son convertidos en entidades inertes, en objetos que sirven otros fines -como ser el suelo por donde escurre el agua- cuya existencia no tiene valor en sí misma.

Un ejemplo de lo anterior son las definiciones, procedimientos y prácticas de la Dirección General de Aguas (DGA), el organismo público a cargo de la regulación del agua. Las atribuciones de la DGA en relación a los humedales se refieren al agua y al cauce que son parte de estos ambientes, entendiendo por cauce el suelo por donde escurre el agua. En particular, a la DGA le corresponde asignar y vigilar los derechos de aprovechamiento de aguas y fiscalizar las obras susceptibles de modificar los cauces. Tales obras incluyen, por cierto, aquellas con fines de urbanización. Mientras el escurrimiento de las aguas, la recarga de acuíferos y los derechos de agua no se vean afectados, para la DGA las normas a su cargo están siendo correctamente cumplidas, independientemente de si los humedales son o no intervenidos de una manera que afecte sus funciones ecológicas. Más aún, frente a denuncias ciudadanas y acciones de fiscalización, la DGA ha sido consistente en señalar que carece de responsabilidad sobre los humedales en cuanto tales y que sus atribuciones sólo se refieren al agua y su cauce $^{22}$.

Algo similar ocurre con la Dirección de Obras Hidráulicas (DOH), entidad a la que le corresponde asegurar que la red primaria y de disposición final para la evacuación y drenaje de aguas Iluvia funcione correctamente en las áreas urbanas. En este contexto, para la $\mathrm{DOH}$ los humedales son parte de la "infraestructura" que las ciudades requieren para que las aguas lluvia escurran ${ }^{23}$. No obstante, en base a la normativa vigente, este organismo no ve inconveniente en que los humedales sean alterados ecológicamente e incluso reemplazados por infraestructura hidráulica artificial (p.e. tuberías o canales), siempre que la capacidad para evacuar aguas lluvia no se vea disminuida. En palabras de un entrevistado de la $\mathrm{DOH}$ en Valdivia, si un humedal "se rellena [pero] el cauce se mantiene, no hay problema (....). Solo nos preocupamos que la ciudad no se inunde" 24 .

En suma, tanto para la DGA como para la $\mathrm{DOH}$ los humedales son resguardados en tanto cumplen funciones de abaste-cimiento, captación y conducción de aguas Iluvia, siendo

22 Esto se ejemplifica en la respuesta de la DGA a una denuncia ciudadana realizada en 2015 (Expediente FV-1401-35, DGA, 23 Junio 2015) por intervención y relleno de un afluente del Humedal Angachilla. La DGA expresó que: "La DGA tiene competencia en la parte del Humedal que corresponde a cauce natural, entendiendo que el humedal es un concepto más amplio desde el punto de vista de su extensión y ecosistema, por lo que la denuncia sólo es acogida en la parte que se refiere a la modificación de un cauce natural, sin pronunciarse sobre el eventual efecto ambiental de la intervención sobre el humedal". Ver Guerra y Lara-Sutulov (2017).

23 El respectivo Plan Maestro de Aguas Lluvia de Valdivia (2015) reconoce 653,6 ha de humedales urbanos y los define como una "infraestructura" suficiente para que la ciudad capte y canalice las aguas lluvia, valorando así su existencia y la función hidrológica y de protección contra inundaciones que cumplen.

24 Entrevista a funcionario de la DOH Valdivia, octubre, 2016 
irrelevante si son intervenidos y afectados en sus propiedades ecológicas. Más aún, si bien la intervención de "cauces" -incluyendo su relleno- requiere autorización de la DGA, en Valdivia esta práctica ha sido favorecida por una fiscalización complaciente. En efecto, en el caso de "cauces" localizados dentro de propiedades privadas que han sido intervenidos sin autorización de la DGA, ha primado el criterio de que, por no corresponder a bienes nacionales de uso público, no existe una real infracción (Guerra y Lara-Sutulov 2017).

A diferencia de las normativas que rigen a la DGA y la $\mathrm{DOH}$, los instrumentos de planificación sí reconocen a los humedales como ecosistemas. Este es el caso del proyecto de modificación del Plan Regulador Comunal (PRC) de Valdivia, el principal instrumento de planificación urbana, hoy en trámite de aprobación. En efecto, el proyecto de PRC reconoce a los humedales urbanos como elementos patrimoniales $y$ menciona su condición de "macroecosistema", señalando que éste es determinante de la morfología de la ciudad y cumple además una función clave ante el riesgo de inundaciones. Más aún, el proyecto de PRC reconoce la demanda social por restringir la habitabilidad de estos ambientes.

No obstante, el proyecto de PRC eliminó la clasificación previa de los humedales urbanos como "áreas de protección de recursos de valor natural" y los redefinió bajo la categoría de "áreas de riesgo". Además, el proyecto de nuevo PRC diferenció a los humedales de los "hualves" - o bosques pantanosos- y de las vegas. Mientras en las zonas identificadas como humedales, el PRC permite usos compatibles con la creación de áreas verdes y espacios públicos, en las zonas ahora clasificadas como "hualves" y vegas permite equipamientos y cierto tipo de edificación. Ni la clasificación que el PRC propone de los humedales urbanos de Valdivia -en humedales, hualves y vegas-, ni su jerarquización según los usos permitidos o no en ellos, responden a criterios técnicosambientales claros. Menos aún el que algunos humedales -en este caso, los "hualves" y vegas- queden expuestos a ser intervenidos y eventualmente urbanizados ${ }^{25}$. Las posibles consecuencias que el PRC podría tener sobre algunos humedales de Valdivia evidencia el poder performativo que se deriva de este tipo de instrumentos.

Fue por este tipo de efectos, que el proyecto de PRC -que en 2018 fue rechazado por tercera vez por la Contraloría- desató una intensa controversia desde que se hiciera público, en el 2012. La Red Ciudadana por los Humedales -una agrupación de organizaciones sociales, ambientales y académicas de Valdiviaha cuestionado, precisamente, la manera inconsistente y peligrosa en que el proyecto de PRC define y clasifica a los humedales de Valdivia: por un lado, como ambientes valiosos, que deben ser reconocidos y protegidos $y$, por otro, como espacios sin un uso relevante, eventualmente disponibles para la expansión

25 Hasta 2012, la propuesta de PRC consideraba gran parte de los Humedales Urbanos como Áreas de Protección de Recursos de Valor Natural, diferenciando entre Humedales (Zona P-2) o Hualves y Vegas (Zona P-3). En la propuesta actual los humedales son clasificados como "áreas de riesgo". Los bordes de cauces, esteros y quebradas (muchos de los cuales son humedales) han quedado como Áreas de Riesgo por Inundación (Ri-1), mientras los humedales, hualves y vegas han sido clasificados como Áreas Potencialmente Inundables (Ri-4 y Ri-5). Las áreas Ri-1 y Ri-4 se encuentran relativamente bien protegidas, ya que sólo se permite el uso de suelo para áreas verdes y espacio público, por lo que la posibilidad de edificar sobre estas áreas está restringida a este tipo de proyectos. Mientras que las áreas Ri-5 (hualves y vegas), han quedado con una protección menor, ya que en ellas se permite la construcción de equipamiento con destino científico, comercial (restaurantes y cafeterías), culto y cultura, deportivo, de servicios artesanales y sociales. 
urbana. Con ello, el proyecto de PRC refuerza la "ontología débil" con que las normas y políticas nacionales también performan a los humedales. Esta discusión también ha permeado el proceso de elaboración y aplicación de la Ordenanza Comunal de Protección de Humedales, aprobada en Valdivia en Febrero de 2016, luego de un intenso trabajo impulsado por la Red Ciudadana ya mencionada (Lara Sutulov 2017). En efecto, los actores que han sido parte del proceso de aprobación de la ordenanza de humedales cuestionan que el Municipio persista en dilatar las medidas que permitirían avanzar en su protección efectiva, restando relevancia a la necesidad de sancionar su relleno. Estas dificultades son comunes a varias otras ordenanzas comunales de humedales vigentes en Chile, reflejando su debilidad jurídica. No obstante, estas normas locales han sido impulsadas desde el 2012 por el MMA como una de las principales herramientas para la protección de estos ecosistemas en Chile (Tecklin, Sepúlveda y Lara 2015).

A nivel regional, la propuesta de Plan Regional de Ordenamiento Territorial (PROT) -el principal instrumento de planificación territorial, a cargo del Gobierno Regional- también reconoce a los humedales como ecosistemas relevantes. El PROT, cuyo diseño fue iniciado el 2009, se encuentra en la fase final de aprobación. Reconoce a los humedales como elementos estructurantes del paisaje y parte del patrimonio natural de la Región. Consistente con ello, la propuesta del PROT incluyó a los humedales en las zonificaciones de usos propuestas para el territorio. En particular, destaca el hecho que el proceso de elaboración del PROT incluyera información territorial detallada sobre algunos humedales. Es el caso del humedal del Río Cruces y sus ríos tributarios, para el cual el
PROT propone una zonificación compatible con su protección. Asimismo, destaca la zonificación que el PROT propone para el espacio urbano de Valdivia, siendo la categoría "humedales" una de las cuatro unidades de planificación con que reagrupa las zonas identificadas por el PRC. A diferencia del PRC y las políticas y normas sectoriales, el PROT contribuye a performar humedales con una "ontología fuerte", lo que favorece su protección. No obstante, a diferencia del PRC este instrumento no es vinculante. Además, su aprobación no ha concluido.

En suma, la "ontología débil" que los humedales tienen en las normas y políticas nacionales se replica a escala regional y local por medio de dos tendencias complementarias. Por una parte, las normas sectoriales desmembran a los humedales en componentes como "agua" y "cauces", ignorando su condición de ecosistemas y favoreciendo intervenciones que afectan sus propiedades y funcionalidad, por ejemplo a través de su relleno. Por otra parte, los instrumentos que sí reconocen a los humedales en cuanto ecosistemas, atribuyéndoles una "ontología fuerte" asociada a su valor tanto ecológico como social -como es el caso de la planificación regional y urbana- fallan en aportar herramientas para su protección efectiva. En el caso del PRC, los humedales se clasifican en categorías discutibles, cuya jerarquización expone a una parte de los mismos como áreas de menor valor $\mathrm{y}$, por ende, sujetas a la degradación y el relleno.

No obstante la visibilidad alcanzada por los humedales y, asociado a ello, el reconocimiento de sus valores y funciones ecológicas y sociales por parte de instrumentos de planificación territorial, las prácticas dominantes de relación con los humedales urbanos de Valdivia siguen 
estando al servicio del crecimiento de la ciudad. Esta inconsistencia se sostiene gracias a la "ontología débil" que hoy caracteriza a los humedales urbanos. Es decir, una forma de existencia que, si bien, ha sido por fin reconocida y valorada, está insuficientemente entrelazada con las redes de conocimientos, identidades y recursos que determinan el devenir de la ciudad. Ello impide la movilización de acciones y dispositivos que aseguren la permanencia material de los humedales urbanos de Valdivia en el tiempo.

Aquí proponemos que esta "ontología débil" ha comenzado a ser desafiada por nuevas prácticas de relación con los humedales urbanos de Valdivia, surgidas con posterioridad al desastre del Río Cruces. Dichas prácticas han tomado forma, en particular, a través de iniciativas locales para la protección y defensa de los humedales, las que revisamos a continuación.

\section{Prácticas y ontologías de protección ciudadana de los humedales de Valdivia}

Como se señaló en la introducción, el desastre del Río Cruces, ocurrido a partir del 2004, hizo por primera vez visibles a los humedales urbanos en tanto objetos de atención de las políticas públicas. Este evento marcó un quiebre en la trayectoria previa de relleno y destrucción de estos ambientes, establecida como dominante a lo largo de casi dos siglos.

El desastre del Río Cruces desestabilizó esta tendencia dominante al evidenciar de forma dramática los valores ecológicos de los humedales urbanos de Valdivia. En ello, los cisnes jugaron un papel determinante. Al refugiarse en áreas inundadas localizadas en medio de la ciudad mientras escapaban de la contaminación que los afectaba, los cisnes del Río Cruces hicieron visibles las propiedades ecológicas de los humedales urbanos. Los valdivianos comenzaron así a "descubrir" que en sus propios vecindarios existían ambientes capaces de ofrecer refugio a los cisnes $y$, por tanto, igualmente valiosos en términos ecológicos (Skewes et al. 2012). Lo que hasta entonces eran terrenos "baldíos" o microbasurales, candidatos al relleno, adquirieron -mediados por la agencia de los cisnes contaminados-, la condición de áreas que ameritaban protección.

Como efecto del desastre, por tanto, los humedales urbanos cobraron una visibilidad inédita en Valdivia, protagonizando controversias en torno al uso del espacio urbano y la ejecución de proyectos inmobiliarios y de infraestructura vial, asuntos que una década atrás no concitaban debate.

Esta naciente valoración de los humedales urbanos de Valdivia trajo consigo una consecuencia imprevista: el surgimiento de iniciativas comunitarias para su protección y defensa, protagonizadas en particular por vecinos de barrios periféricos de la ciudad. En efecto, en resonancia con la multitudinaria movilización valdiviana que demandó la protección del humedal del Río Cruces, los habitantes de barrios populares comenzaron a cuidar sus propios humedales y a demandar su resguardo oficial. Concretamente, estos humedales periféricos comenzaron a ser vistos como potenciales áreas verdes donde los pobladores pudieran recrearse, hacer deporte, realizar actividades educativas $\mathrm{y}$, más ampliamente, "acercarse" a la naturaleza. De esta forma, los humedales ingresaron de lleno a 
la vida cotidiana de los pobladores valdivianos, ampliando sus imaginarios sobre la ciudad.

Nutrida por estos debates, desde el 2012 tomó forma una red ciudadana por la defensa de los humedales urbanos, integrada por actores vecinales vinculados a las iniciativas de protección de humedales, así como por ONG locales, profesionales y expertos. La principal demanda de esta Red -que formalizó su existencia en el 2015- ha sido el reconocimiento de los humedales urbanos como sitios de valor ecológico y social y, asociado a ello, la implementación de medidas efectivas de protección por parte de organismos como el MMA, la DGA, la DOH y la Municipalidad. En particular, la Red Ciudadana ha demandado detener el relleno ilegal de humedales que se ha convertido en una práctica sistemática del crecimiento de la ciudad. Un hito en este proceso fue la instalación en el 2014 de una Mesa Técnica Comunal de Humedales que consiguió la aprobación de la ordenanza comunal de humedales ya mencionada a comienzos del 2016, luego de una larga resistencia por las autoridades municipales (Lara Sutulov 2017).

Entre las iniciativas locales de protección y defensa de los humedales surgidas recientemente en Valdivia, destacan los casos del Humedal y Parque Urbano Catrico y de la Reserva Natural Urbana Angachilla, impulsadas desde el 2007 por agrupaciones de vecinos. Ambas iniciativas buscan recuperar humedales considerados emblemáticos para la ciudad. Teniendo en cuenta las redes de actores y las acciones articuladas en torno a ellos, sostenemos que estas dos iniciativas comunitarias han sido exitosas en dotar a los humedales Catrico y Angachilla de una "ontología fuerte". Es decir, de una existencia capaz, no sólo de ser reconocida y valorada, sino de movilizar conocimientos, recursos y medidas en favor de su protección y restauración ${ }^{26}$. A continuación revisamos el proceso por medio del cual ambos humedales han sido dotados de una "ontología fuerte" a través de la acción ciudadana.

\section{Parque Urbano y Deportivo Catrico}

La iniciativa de protección del Humedal Catrico es una de las experiencias más importantes de movilización por la defensa de un humedal urbano ocurrida en Valdivia. Este humedal de 40 hectáreas colinda con un gran sector en la zona sur de la ciudad, donde se localizan las poblaciones Yáñez Zabala, San Luis, Pablo Neruda, San Pedro, Cau-Cau Nagasaki y Los Alcaldes. Inspirados en la movilización de Acción por los Cisnes, iniciada el 2004 en defensa del humedal del Río Cruces, dirigentes de estas poblaciones iniciaron un proceso comunitario para rescatar el Humedal Catrico, el que se ha extendido por más de una década. Los dirigentes reconocen que "este proyecto (...) nace de la conciencia ambiental que nos crea Acción por los Cisnes. (...) ver un basural de los más grandes de Valdivia, donde están los sectores más carenciados de la ciudad, donde nadie se fijó que se podía hacer un parque. Y bueno... se levanta el movimiento ciudadano"27.

La movilización comunitaria se centró en reivindicar al humedal, por largo tiempo utilizado como micro-basural y considerado un lugar

26 Esta "ontología fuerte" también ha venido acompañada de riesgos, como la dificultad de los vecinos de ser una contraparte sólida del Estado y las empresas a cargo de ejecutar las millonarias obras de inversión aprobadas para convertir el Humedal Catrico en un parque urbano.

27 Entrevista realizada en el marco de la investigación doctoral "Cisnes, disputas ecológicas y aperturas ontológicas: una visión posthumanista de los efectos institucionales de largo plazo derivados del desastre del Río Cruces, en Valdivia, Chile". 
inseguro, como un sitio "valioso", que ameritaba ser protegido. Para los vecinos, esta valoración no ha sido sólo ecológica sino también social. Es más, ambas dimensiones son indistinguibles en las prácticas locales de protección. La visión de estos pobladores ha sido la de "integrar" el humedal como espacio habitable, a fin de potenciar servicios que asociados a su condición de área natural, los que son escasos en zonas populares de Valdivia. Estos servicios incluyen recreación al aire libre, avistamiento de aves, prácticas deportivas y actividades culturales.

A partir de esta revalorización se fue configurando una demanda comunitaria por convertir el humedal en un parque urbano, cultural y deportivo. Con tal fin se constituyó una agrupación de más de 40 juntas vecinales, que logró el apoyo de actores políticos, sociales y académicos. Aunque estas aspiraciones han chocado con proyectos de urbanización y varios desafíos políticos y financieros, la iniciativa de recuperación del Humedal Catrico se instaló en la agenda de autoridades y servicios públicos, convirtiendo al Parque Urbano y Deportivo Catrico (www.parqueurbanocatrico.cl) en un proyecto oficial, con financiamiento del Gobierno Regional y el Ministerio de Vivienda. De forma notable, el diseño de este parque urbano se realizó de manera participativa. Otro éxito de la demanda comunitaria y ciudadana es el programa de capacitación y difusión en temas ambientales para los vecinos del humedal, ejecutado por una organización compuesta en parte por dirigentes del movimiento y financiado por el Fondo Nacional de Desarrollo Regional (FNDR).

La fase de construcción, iniciada el 2015, ha atravesado por varias dificultades, incluyendo la intervención del humedal con maquinaria pesada y cemento, además de la quiebra de la empresa a cargo de la construcción. No obstante, esta iniciativa sigue siendo un referente que ha fortalecido y movilizado imaginarios alternativos sobre la ciudad.

\section{Humedal Angachilla}

La iniciativa de protección comunitaria del Humedal Angachilla -de 137 hectáreas, también localizado en la zona sur de Valdiviaha sido impulsada por vecinos de la Villa Claro de Luna, un barrio nuevo de viviendas sociales, establecido a fines de la década de 1990. Los vecinos "descubrieron" el valor ambiental del área e iniciaron acciones a favor de su protección en gran medida como efecto del desastre del humedal del Río Cruces. De acuerdo a Skewes et al. (2012: 140), dicho evento fomentó la conciencia ambiental de los vecinos por medio de "la visualización y percepción de las consecuencias de un desastre ambiental". Así lo reconocen vecinos como Fredy Vargas Barría, quien es hoy el "guardián" del Humedal Angachilla. Este vecino relata de la siguiente manera el efecto que el desastre del Río Cruces provocó en la relación de los pobladores con el Humedal Angachilla: "Producto de ver como sufrían las avecitas enfermas y desnutridas, los vecinos $y$ pobladores comenzamos a sentir la necesidad de proteger a los cisnes y a otras aves nativas. También comenzamos a comprender que los humedales son valiosos porque, precisamente, sirven de refugio a estas aves y a la vida silvestre. Antes, el común de las personas veía estos sitios como espacios para botar basura. Después del desastre del Río Cruces eso cambió rotundamente" (Vargas Barría 2018, en prensa).

A mediados de los 2000, el entonces Presidente de la Junta de Vecinos de la Villa Claro de 
Luna, Jaime Rosales, junto a Fredy Vargas y otros vecinos, comenzaron a limpiar la zona del humedal aledaña al sector habitado. Con ello, buscaban tanto recuperar su valor natural como convertirla en un sitio más limpio y seguro para los pobladores. El año 2007, enterados de la iniciativa de crear un parque urbano en el Humedal Catrico, estos vecinos postularon a fondos concursables para habilitar un área protegida autogestionada. Así, construyeron senderos, miradores y señalética, plantaron árboles y realizaron campañas de limpieza. Por sus sobresalientes valores naturales, el humedal visibilizado por medio de estas acciones comunitarias, movilizó el apoyo de muchos otros actores, incluyendo estudiantes universitarios y organizaciones ciudadanas. El año 2010 el lugar fue declarado Reserva Natural Urbana por los propios vecinos, categoría promovida por la Agrupación Biósfera, mientras el 2011 se constituyó el Comité Ecológico Angachilla, en apoyo a su protección.

Desde el 2012 el Humedal Angachilla está amenazado por la Avenida Circunvalación Sur, una nueva carretera urbana a cargo del Servicio de Vivienda y Urbanismo, que contempla un terraplén que dividiría en dos el espejo de agua principal. El proyecto cuenta con la aprobación del Consejo Municipal28. Aunque por tratarse de una obra pública no es obligatorio que este proyecto urbano ingrese a evaluación ambiental, ha generado una gran controversia debido a los impactos irreversibles que podría generar en la condición del Humedal Angachilla como hábitat para numerosas especies de fauna acuática y espacio para la recreación y contemplación. Este

El martes 14 de septiembre del 2012, el Concejo Municipal de Valdivia dio su aprobación a la construcción de la Avenida Circunvalación Sur. Este proyecto del SERVIU fue respaldado por la mayoría de los concejales presentes. conflicto, sumado a la movilización constante de los vecinos de la Villa Claro de Luna por cuidar este humedal y habilitarlo como área protegida, ha convertido al Humedal Angachilla en un sitio considerado hoy como patrimonio de la ciudad de Valdivia.

Las iniciativas de protección de los humedales Catrico y Angachilla marcan el inicio de lo que con los años se ha convertido en una sostenida movilización ciudadana para proteger, recuperar y detener la destrucción de estos ambientes urbanos. A ellas se han sumado iniciativas similares en torno a los humedales Santa Inés, Los Pelúes, Leña Seca, Cau-Cau y Krahmer, localizados en distintos barrios de la ciudad. Cabe destacar que no todos ellos corresponden a humedales ecológicamente valiosos. En el caso del Humedal Cau-Cau, por ejemplo, un área bastante degradada, la construcción de un nuevo cuartel de la Policía de Investigaciones de Valdivia fue en su momento resistida por vecinos que pedían convertirla en un área verde. Este caso confirma que, independientemente de sus valores ecológicos, los humedales urbanos de Valdivia son hoy capaces de movilizar imaginarios alternativos de la ciudad asociados a valores como el acceso igualitario a espacios naturales y los servicios asociados a ellos, así como a la demanda por participación en las decisiones sobre cómo se construye la ciudad.

Proponemos que estas movilizaciones ciudadanas no solo han fortalecido ontológicamente a los humedales urbanos de Valdivia al conectarlos a redes de actores, categorías de protección, programas y recursos públicos, además de prácticas de socialidad en torno a la naturaleza a través de educación ambiental, ciclismo, kayakismo, danza, fotografía, avistamiento de aves y juego del 
palín, entre muchas actividades que los vecinos practican en estos espacios, convertidos por ellos mismos en áreas protegidas urbanas. Más aún, sostenemos que estas prácticas han dado origen a una multiplicidad de humedales, los que han adquirido nuevas e impensadas identidades vinculadas a la vida cotidiana de los barrios y, en particular, a sus luchas por la inclusión social. Así, en contraste con los humedales que las normas y políticas públicas han convertido en entes fragmentados y difusos, los humedales performados por los pobladores de Valdivia son entidades fuertes, multidimensionales, y capaces de actuar como "aliados" en la construcción de una ciudad más justa.

Entre los múltiples humedales que han tomado forma y co-existen a través de estas iniciativas, destacan los siguientes, vinculados a prácticas específicas:

- Los humedales son espacios en torno a los que se desarrollan nuevas maneras de co existir con los espacios naturales al interior de la ciudad. A través de ellos, la naturaleza ya no es un lugar extraño o exterior a la ciudad, sino "integrada" a ella y formando parte de la vida cotidiana de sus habitantes. En estos humedales se cultivan alimentos y se educa a los niños. También se danza, se practican deportes, se avistan aves y se celebran las fiestas de los barrios.

- Los humedales son espacios naturales que, convertidos en parques o reservas, ofrecen a los habitantes de sectores populares lugares donde recrearse y disfrutar de la vida al aire libre. Con ello, la protección de los humedales, en especial si es por medio de inversiones públicas, repara en parte la injusta distribución de espacios verdes urbanos. Estos humedales son aliados de la reivindicación por una ciudad menos desigual.

- Los humedales son ecosistemas cuya identificación, clasificación, evaluación y defensa circula por seminarios, mesas técnicas, informes de consultoría y cartografías varias. Estos humedales son objetos de análisis científicos y jurídicos en cuanto ecosistemas propiamente, con funciones ecológicas reconocidas. Son además actores centrales de las controversias y movilizaciones que demandan su reconocimiento por los instrumentos de planificación urbana, de los cuales depende en gran medida su destino.

- Los humedales son actores capaces de aliarse con organizaciones sociales de los barrios populares de Valdivia, y sus capacidades de participación e incidencia en las políticas y decisiones sobre el desarrollo de la ciudad. Estos humedales contribuyen a hacer visibles las relaciones de poder entre los habitantes de zonas populares y los de otros barrios de la ciudad.

\section{Humedales e imaginarios alternativos de la ciudad}

Las movilizaciones en torno a los humedales en Valdivia están contribuyendo a la reconfiguración de la identidad de Valdivia, iniciada hace más de una década como efecto del desastre del Río Cruces (Sepúlveda 2016, 2018). La imagen de Valdivia como ciudad industrial -dominante hasta los años 1990- facilitó la aprobación en 1998 de la planta de celulosa que descargaría 
sus desechos al humedal del Río Cruces. Hoy, dicho pasado industrial es parte de un imaginario de Valdivia cada vez menos "denso", ontológicamente hablando. En su lugar ha comenzado a tomar forma una nueva identidad urbana, mucho más conectada con los ríos, cuya presencia está estrechamente ligada a la historia de Valdivia y a través de estos cuerpos de agua, a los humedales y sus habitantes no humanos. En efecto, humedales y cisnes en particular se han convertido en nuevos actores de la constitución sociopolítica del espacio urbano (Sepúlveda 2018). Una manifestación de dicho imaginario fue la declaración de Valdivia como "la Ciudad Humedal", realizada por Acción por los Cisnes en el 2005. Con ello, Valdivia pasó a ser, no una ciudad con humedales que ocupan gran parte de su suelo urbano. Más bien, Valdivia se convirtió en una ciudad asentada sobre una red de ambientes húmedos, que cada tanto reemergen junto con los ciclos geotectónicos que moldean este territorio.

Las iniciativas de protección de los humedales urbanos de Valdivia surgidas con posterioridad al 2004 han continuado alimentado imaginarios urbanos alternativos. En ellos la noción de una ciudad más inclusiva, donde el acceso a áreas verdes se distribuya de forma más equitativa, ocupa un lugar central. Así, habilitados como parques y reservas urbanas, los humedales vendrían a reparar una desigualdad social estructural. Ello es consistente con el hecho que las movilizaciones e iniciativas más masivas en defensa de humedales han surgido en barrios periféricos, sin acceso a áreas verdes.

Un segundo tipo de imaginario se vincula al lugar que los humedales podrían llegar a ocupar en cuantos espacios efectivamente protegidos, e integrados al tejido urbano. Es decir, como áreas donde se puedan practicar nuevas formas de co-existencia entre habitantes humanos y remanentes de ecosistemas naturales, como los que aún existen en Valdivia. Entre estos imaginarios destaca la propuesta de crear una Red de Reservas Naturales Urbanas, impulsada por la Agrupación Biósfera, la que protegería de manera oficial los fragmentos de bosques y humedales.

Un tercer imaginario, asociado al anterior, apunta a declarar toda la red de humedales urbanos y periurbanos de Valdivia como una gran área protegida oficial a través, por ejemplo, de la categoría de Santuario de la Naturaleza. De esta forma, la condición de "Ciudad Humedal" quedaría reconocida formalmente. Este imaginario es reconocible en la forma en que los vecinos del Humedal Catrico se refieren a los humedales de Valdivia: "Creemos que los humedales son todos Santuarios de la Naturaleza, lugares ricos en vida que mantienen el equilibrio hídrico de nuestra ciudad (...) Los humedales son parte de nuestra vida, si los destruimos nos destruimos a nosotros mismos"29.

Un imaginario de carácter más empresarial ve a los humedales y su conexión con la red fluvial de Valdivia como componente clave de estrategias de desarrollo capaces de convertir la ciudad en un modelo de desarrollo "sustentable". Este imaginario es liderado por iniciativas como Activa Valdivia y Visión Valdivia ${ }^{30}$, entidades que agrupan a empresas y entes privados, contando con el apoyo de organismos públicos. Estas iniciativas han impulsado proyectos como el

\footnotetext{
29 "Manifiesto del sur de Valdivia, por los retrasos en el Proyecto Parque Catrico", noviembre 27, 2012.

30 Ver http://www.visionvaldivia.cl/proyectos/consorcio-valdiviasustentable y http://www.activavaldivia.cl
} 
diseño de un centro deportivo fluvial, ferias de emprendedores fluviales, un gran puerto fluvial y propuestas de desarrollo urbano que pongan en valor el patrimonio arquitectónico y natural de la ciudad.

Aunque estos imaginarios son incipientes, tienen el potencial de afectar la trayectoria urbana futura de Valdivia. Así lo confirma el reconocimiento que algunos instrumentos de planificación territorial han hecho de los humedales como patrimonio natural que corresponde proteger. También lo confirman, por cierto, las inversiones públicas para habilitar la creación del Parque Urbano y Deportivo Catrico y, aunque en escala menor, la habilitación del Humedal Angachilla como Reserva Natural Urbana. Finalmente, estos imaginarios se fortalecen y aumentan su capacidad de incidir en la trayectoria de la ciudad por medio de las controversias públicas en torno a proyectos o decisiones que podrían llevar a la destrucción de algunos humedales.

\section{Conclusiones}

Los humedales gozan hoy globalmente de una sólida reputación debido a la crítica función que cumplen en la regulación de los ciclos hidrológicos, además de muchos otros servicios ecosistémicos. En Chile, su existencia en cuanto objetos de atención de las políticas públicas fue reconocida solo de manera reciente, luego del desastre que a fines del 2004 afectó al gran humedal del Río Cruces, en Valdivia. Este reconocimiento, sin embargo, no ha sido suficien-te para que los humedales adquieran el estatus de objetos que merecen ser legalmente protegidos. De allí que estos ecosistemas tengan en Chile una "ontología débil". Es decir, una existencia cuya valoración no alcanza para movilizar medidas y recursos en favor de su resguardo efectivo.

En Valdivia, la precariedad ontológica de los humedales ha sido desestabilizada por los efectos generativos del desastre del Río Cruces. Este evento puso en cuestión la posición de marginalidad que los humedales de Valdivia ocuparon durante décadas, convertidos en espacios devaluados y en micro-basurales. Como efecto de dicho desastre y, en particular, mediados por la agencia de los cisnes -que se refugiaronenellosalescapardelacontaminación-, los humedales se volvieron por primera vez visibles como lugares ecológica y socialmente valiosos, que merecían ser protegidos. Así, organizaciones de barrios populares impulsaron iniciativas para transformar grandes zonas inundadas en parques o reservas urbanas. A través de estas movilizaciones los humedales se han convertido en actores protagónicos de la constitución sociopolítica del espacio urbano valdiviano. Cuestionando la forma hasta ahora dominante de performar estos ambientes como "sitios eriazos", los pobladores también han confrontado la trayectoria de desarrollo de la ciudad. Con ello, han puesto en tensión la segregación urbana expresada, entre otras cosas, en la baja presencia de áreas verdes en los barrios periféricos.

Igualmente relevante, las acciones comunitarias de protección de humedales urbanos han construido una nueva socialidad en torno a la naturaleza. Los humedales han sido "integrados" a la vida cotidiana de los pobladores por medio de un despliegue de prácticas, tanto de convivencia social como de cuidado ecológico. Ello no sólo ha fortalecido ontológicamente a los humedales, que hoy muestran en Valdivia una notable capacidad de movilizar medidas y 
recursos en favor de su existencia. Tales prácticas también han multiplicado ontológicamente a los humedales. Así, los humedales de Valdivia exhiben hoy identidades diversas, según sean los circuitos sociopolíticos por donde circulen y las redes de actores con que se relacionen.

\section{Agradecimientos}

Las autoras agradecen a Fondecyt por su apoyo a esta investigación a través del Proyecto 1141011 y al Centro de Estudios Ambientales de la Universidad Austral de Chile.

\section{Bibliografía}

Almonacid, F. 2002. "Ideas y Proyectos en torno a la vivienda obrera en la ciudad de Valdivia, 1900-1941". Revista Austral de Ciencias Sociales 4: 81-114.

Arenas, D., Córdoba, J. y P. Lira. 2008. Informe Final de Evaluación. Programa de Recursos Naturales y Biodiversidad. CONAMA.

Bernales, M. 1984. "Aspectos diacrónicos en la toponimia de Valdivia". Anales de la Universidad de Chile 5: 79-94.

Blaser, M. 2009. "Political Ontology". Cultural Studies, 23(5-6), 873-896.

Blaser, M. 2010. Storytelling Globalization from the Chaco \& Beyond. Durham, Duke University Press.

Brinson, M. M., y S. D. Eckles. 2011. "U.S. Department of Agriculture conservation program and practice effects on wetland ecosystem services: a synthesis". Ecological Applications 21: 116-127.

Boloña, N. 1896. Plano de Valdivia. Biblioteca Nacional de Chile. Digitalización de Memoria Chilena.

Callon, M. 1986. "Some elements of a sociology of translation: Domestication of the scallops and the fishermen of St. Brieuc Bay". In J. Law (Ed), Power, action and belief: a new sociology of knowledge? (pp. 196-223). London, Routledge.

Callon, M. 2006. What does it mean to say that economics is performative? Papiers de Recherche du CSI. Paris: Centre de Sociologie de L'Innovation, Ecole des Mines de Paris.

Callon, M. 2009. "Elaborating the notion of performativity". Le Libellio d'Aegis, 5(1), 18-29

Comisión Nacional del Medio Ambiente - CONAMA. 2005. "Estrategia Nacional para la Conservación y Uso Racional de los Humedales en Chile". Santiago: Gobierno de Chile.

Comisión Nacional del Medio Ambiente - CONAMA. 2005b. "Política Nacional de Áreas Protegidas". Santiago: CONAMA.

Consejo de Defensa del Estado. 1991. Ordinario 006459, 3 de julio, 1991. Informe sobre dominio de terrenos recuperados al río por obras de ingeniería.

Convención Ramsar (2012). "Los Humedales Cuidan del agua" http://www.ramsar.org/sites/default/files/documents/ library/leaflet_s_0.pdf

El Mercurio, 24 noviembre 2005, "CONAMA: Es necesaria una mejor regulación."
El Mercurio, 12 junio 2008, Columna de Andrés Concha: "Los cisnes y el Ministerio de Medio Ambiente."

El Mercurio, 10 junio 2005, "Rigor medioambiental: Privados temen escalada de búsqueda de nuevos Celcazos." Juan Meriches y Lina Castañeda. Economía y Negocios.

Escobar, A. 2007a. "The 'ontological turn' in social theory: A Commentary on 'Human geography without scale', by Sallie Marston, John Paul Jones II and Keith Woodward". Transactions of the Institute of British Geography, 32, 106-111.

Escobar, A. 2007b. "Worlds and knowledges otherwise". Cultural Studies, 21(2), 179-210.

Fariña, J. M. y Camaño, A. 2012. Humedales Costeros de Chile: Aportes científicos a su gestión sustentable. Santiago: Ediciones Universidad Católica de Chile.

Finlayson, M. 2012. "Forty years of wetland conservation and wise use" Aquatic Conservation. 22 (2): 139-143.

Gobierno de Chile. 2015. "Informe Nacional de Chile Sobre la Aplicación dela Convención de Ramsar sobre los Humedales a ser presentado en la $12^{\mathrm{a}}$ Reunión de la Conferencia de las Partes Contratantes" Santiago: Ministerio de Relaciones Exteriores de Chile.

Guarda, G. 2001. Nueva Historia de Valdivia. Santiago: Ediciones Universidad Católica de Chile.

Guarda, G. 1993. Una ciudad chilena del siglo XVI. Valdivia 1552-1604. Santiago: Ediciones Universidad Católica de Chile.

Guerra, F. y Lara-Sutulov, M. 2017. “¿Públicos o privados? Desafíos para la protección de los humedales urbanos y periurbanos de Valdivia a partir de la regulación de los cauces naturales". Revista de Derecho Ambiental. (8), pp. 184-206. doi:10.5354/0719-4633.2017.47916.

Jacques, A. 2012. "Reservas Naturales Urbanas: Diagnóstico de la Percepción y la Valoración Socio-Cultural sobre la vegetación urbana de la ciudad de Valdivia", Memoria para optar al grado de Geógrafo. Facultad de Arquitectura y Urbanismo Escuela de Geografía. Universidad de Chile.

Lara Sutulov, M. 2017. "La ordenanza de protección de humedales de Valdivia: una construcción ciudadana en respuesta a la desprotección de los humedales urbanos". Revista Planeo. No31.

Latour, B. y Woolgar, S. 1986. Laboratory Life: the social construction of scientific facts. 2nd edition. Princeton, New 
Jersey: Princeton University Press.

Latour, B. y Woolgar, S., 1979. Laboratory life: The social construction of scientific facts. Beverly Hills.

Latour, B. 2005. Reassembling the social: an introduction to actor-network-theory. New York: Oxford University Press.

Law, J. 2008. "On sociology and STS". The Sociological Review, 56(4), 624-649.

Ministerio de Medio Ambiente - MMA. 2017. Estrategia Nacional de Biodiversidad 2017-2030.

Ministerio de Medio Ambiente - MMA. 2011. Diseño de inventario nacional de humedales y su seguimiento ambiental. Centro de Ecología Aplicada. Santiago: MMA.

Ministerio de Medio Ambiente - MMA. 2013. Revisión de los Planes de Acción de la Estrategia Nacional de Biodiversidad (ENB) año 2003.Santiago: MMA.

Ministerio del Medio Ambiente - MMA. 2016. "Levantamiento de Información Bibliográfica y Cartográfica de los Humedales Urbanos de la Ciudad de Valdivia". Informe Final Licitación № 613925-7 L115, preparado por Montserrat Lara Sutulov y Julio Gerding. Valdivia: MMA.

Ministerio del Medio Ambiente - MMA. 2017. Estrategia Nacional de Biodiversidad 2017-2030.

Mol, A. 1999. "Ontological politics: a word and some questions". In J. Law \& J. Hassard (Eds) Actor Network Theory and Alter (pp. 74-89). Malden, MA: The Sociological Review.

Mol, A. 2002. The Body Multiple. Durham, NC: Duke University Press.

Möller, P. y Muñoz-Pedreros, A. 2014. "Legal protection assessment of different inland wetlands in Chile." Revista Chilena de Historia Natural 87 (1), 23.

Organización de las Naciones Unidas - ONU. 2013. Año Internacional de la cooperación en la esfera del agua. http://www.un.org/es/events/worldwateryear/

Osorio, C. 2009. "Impacto del crecimiento urbano en el medio ambiente del humedal de Valdivia 1992-2007". Tesis para optar al grado académico de Magíster en Asentamientos Urbanos y Medio Ambiente, Instituto de Estudios Urbanos y Territoriales. Pontificia Universidad Católica de Chile.

Otero, L. 2006. La huella del fuego. Historia de los bosques nativos, poblamiento y cambios en el paisaje del sur de Chile. Santiago: Editorial Pehuén.

Pérez Díaz, S. 2015. "Prácticas sociomateriales de relación con los humedales de la ciudad Valdivia, desde su fundación, en 1552, hasta el año 2014." Tesis de Licenciatura en Antropología, Universidad Austral de Chile.

Pizarro, R. 2007. "La Reforma Ambiental en Chile." Journal of Technology, Management and Innovation 2 (2): 3-6.

Radio Cooperativa, 2 de mayo de 2007, "Lagos aseguró que marcó 'un antes y un después' en materia ambiental”.
Convención Ramsar. 2012. Los Humedales Cuidan del agua http://www.ramsar.org/sites/default/files/documents/ library/leaflet_s_0.pdf

Reinhardt, E. G., R. B. Nairn, and G. López. 2010 "Recovery Estimates for the Rio Cruces after the May 1960 Chilean Earthquake." Marine Geology 269 (1): 18-33.

Rivera, C. 2010. "Internacionalización de movimientos sociales. ¿Cuán efectivas son las redes transnacionales de apoyo?", Papeles de Política, 15(2): 617-636.

Rojas, C. 2010. Valdivia 1960, Entre Aguas y Escombros. Valdivia: Ediciones Universidad Austral de Chile.

Rojas, C. 2004. "El rol de los paleocauces y humedales en la evaluación de las amenazas naturales en la ciudad de Valdivia." Revista Geográfica de Valparaíso, 35: 243-251.

Rojas Hoppe, C. y Díez Lorente, S. 2013. "El terremoto chileno del 27 de febrero de 2010: análisis preliminar de las consecuencias en la ciudad de Valdivia". Investigaciones Geográficas 60: 139-153.

Rosales, Diego de. 1877. Historia General del Reyno de Chile Flandes Indiano. Valparaiso: Imprenta del Mercurio.

Sepúlveda, C. y Bettati, B. 2005. "El desastre ecológico del Santuario del Río Cruces: Trizadura institucional y retroceso democrático", Ambiente y Desarrollo 20-21(3-1): 62-68.

Sepúlveda, C. y Rojas, A. 2010. "Conflictos ambientales y reforma ambiental en Chile: una oportunidad desaprovechada de aprendizaje institucional sobre participación ciudadana", Ambiente y Desarollo 24(2): 1523.

Sepúlveda, C. y Villarroel, P. 2010. "Desastre ecológico de CELCO en el Santuario Río Cruces: trizadura institucional y retroceso democrático". En Conflictos por el agua en Chile: Entre los derechos humanos y las reglas del Mercado, Sara Larraín y Pamela Poo (eds). Santiago, Chile: Programa Chile Sustentable: 318-338.

Sepúlveda, C. 2016. "Swans, Ecological Struggles and Ontological Fractures: A Posthumanist Account of the Río Cruces Disaster in Valdivia, Chile." Electronic Theses and Dissertations (ETDs) 2008+. T, University of British Columbia. DOI:http://dx.doi.org/10.14288/1.0225870.

Sepúlveda Luque, C y Sundberg, J. 2015. "Aperturas ontológicas, multiplicidad y performación: ampliando la agenda de una Ecología Política Posthumanista a partir de reflexiones sobre el desastre del Río Cruces, en Valdivia". En Beatriz Bustos, Manuel Prieto y Jonathan Barton (Editores) "Ecología Política en Chile: poder, naturaleza, conocimiento y". Editorial Universitaria.

Sepúlveda-Luque, C. 2018 Bringing animals within political communities: the citizens/swans association that fractured Chile's environmental framework, Social Movement Studies, 17(3): 333-352 DOI: 10.1080/14742837.2018.1459296

Siemsen, E. 1855. Plano de Valdivia. Colección 
Biblioteca Nacional de Chile. Digitalización de Memoria Chilena.

Skewes, J. C., Rehbein, R. y Mancilla, C. 2012. "Ciudadanía y sustentabilidad ambiental en la ciudad: la recuperación del humedal Angachilla y la organización local en la Villa Claro de Luna, Valdivia, Chile". EURE 38(113): 127-145.

Tecklin, D., Bauer, C. y Prieto, M. 2011. "Making environmental law for the market: the emergence, character, and implications of Chile's environmental regime". Environmental Politics, 20(6): 879-898.

Tecklin, D., Sepúlveda Luque, C. y Lara Sutulov, M.
2015. "El espacio para las aves costeras: Análisis del contexto institucional para la protección de hábitat para las aves costeras en Chile, con énfasis en Chiloé". Informe preparado para David and Lucile Packard Foundation. Valdivia.

Urbina, S. y Adán, L. 2012. "La ciudad de Valdivia y su jurisdicción: Elementos para una historia indígena en el período colonial temprano (Ca. 1544-1606)". Ponencia presentada en el V Congreso Nacional de Arqueología Histórica, Buenos Aires, Argentina, 2012.

Vargas Barría, F. 2018. Una pequeña historia del Humedal Angachilla. Valdivia: Editorial Kultrún. En prensa. 